\title{
Incidencia de la banca universal en el sistema financiero venezolano
}

\author{
Nava Rosillón, Marbelis Alejandra*
}

\section{Resumen}

La banca universal es un modelo de banca que ofrece servicios integrales y múltiples con alta eficiencia operativa, mejor gestión de infraestructura y sistemas actualizados para mayor satisfacción de los clientes. Inicia en Venezuela en los años noventa en la búsqueda de modernizar las instituciones financieras. Por ello, esta investigación tiene como objetivo analizar la incidencia de la banca universal en el sistema financiero venezolano ante la fuerte crisis financiera de 1994-1995. Se trata de un estudio descriptivo con diseño documental. La banca universal dio paso a transformaciones, fusiones y adquisiciones de las instituciones financieras especializadas. El Grupo Provincial y Mercantil fueron los primeros en transformarse en banco universal. Hoy, esta banca posee la mayor participación en el Sistema Bancario Nacional, con $45 \%$ de instituciones; $86,79 \%$ de oficinas; $86,33 \%$ de trabajadores; $36,2 \%$ entidades con capital privado, $8,5 \%$ con capital público y altas captaciones. Se concluye que esta banca ha favorecido el sistema financiero venezolano en el largo plazo logrando su mayor fortalecimiento y un mejor funcionamiento mediante una nueva cultura organizacional, generación de empleo, mayor solidez, confianza y credibilidad de ahorristas e inversionistas.

Palabras clave: Banca universal, sistema financiero venezolano, instituciones financieras, intermediación financiera, sistema bancario.

\section{Effect of the Universal Bank on the Venezuelan Financial System}

\begin{abstract}
Abstrac
The universal bank is a bank model that offers integral and multiple services with high operative efficiency, better infrastructure management and up-to-date systems for greater client satisfac-

\section{Recibido: 10-02-11. Aceptado: 11-07-11}

* Economista. Magíster en Gerencia de Empresas, mención: Gerencia Financiera. LUZ. Gerente Administrativo de la Empresa Agropecuaria "Santa Rita". Municipio Sucre. Docente de la Universidad Alonso de Ojeda. Cuidad Ojeda. Municipio Lagunillas. Docente de Postgrado. Universidad Experimental "Rafael María Baralt". Municipio Cabimas. Investigadora acreditada al Programa de Promoción al Investigador (PPI). Estado Zulia, Venezuela.

E-mail: marbejans@hotmail.com; marbejans@cantv.net
\end{abstract}


tion. In Venezuela, these banks appeared in the 1990s in order to modernize financial institutions. The objective of this research is to analyze the effect of the universal bank on Venezuelan financial systems in the light of the intense financial crisis of 1994-1995. The study is descriptive with a documentary design. The universal bank made way for transformations, mergers and acquisitions of specialized financial institutions. The Provincial and Mercantile Group were the first to become universal banks. Today, this type of bank has the greatest share of the National Banking System, including $45 \%$ of the institutions, $86.79 \%$ of the offices, $86.33 \%$ of the workers, $36.2 \%$ of private capital entities, $8.5 \%$ of public capital entities and a high level for raising capital. Conclusions are that the universal bank has favored the Venezuelan financial system in the long run, achieving its greater strengthening and better functioning through a new organizational culture, employment generation, better solidity, confidence and credibility among savers and investors.

Key works: Universal bank, Venezuelan financial system, financial institutions, financial intermediation, banking system.

\section{Introducción}

Hoy en día el proceso de transformación de los mercados, la constante evolución tecnológica y de las telecomunicaciones influye en todos los sectores de la economía y en especial en el sistema financiero; por lo tanto, las organizaciones que lo conforman se ven obligadas a enfrentar continuos cambios y a desarrollar estrategias que les permitan interactuar en nuevos escenarios con el propósito de permanecer en el mercado.

El sistema financiero venezolano (SFV) no escapa de ello; aunado a que este sector ha sufrido una serie de transformaciones en las últimas dos décadas; pues, desde inicios de los años 90 , la inestabilidad económica, política y social del país ha incidido de manera desfavorable en el comportamiento de este sector; conllevando a que durante el período 1994-1995 se produjera una fuerte crisis financiera caracterizada por bancarrotas, intervenciones gubernamentales, procesos de compra-venta, fusiones y adquisiciones de las instituciones financieras nacionales.
Ante tales circunstancias, las autoridades monetarias venezolanas asumieron la necesidad de una modernización y una mayor apertura del sistema financiero $y$ adecuarlo a los nuevos esquemas internacionales, lo cual se visualizaba con amplias perspectivas optimistas y para ello se requería un nuevo marco regulatorio que contribuyera a su saneamiento y al incremento de los niveles de eficiencia; por lo que se aceleró ese proceso y se estableció una nueva Ley del Banco Central en 1992, la modificación de la Ley General de Bancos y otras Instituciones Financieras (LGBOIT) en 1993 y se promulgó la Ley de Regulación de la Emergencia Financiera en 1995. Es importante resaltar que desde entonces las dos primeras leyes antes mencionadas han sufrido una serie de reformas; actualmente la LGBOIT se denomina Ley de Instituciones del Sector Bancario que refiere nuevas modificaciones orientadas a garantizar el funcionamiento del sector bancario para que contribuya al desarrollo económico-social nacional (Asamblea Nacional, 2010).

No obstante, la Reforma de la LGBOIF para 1993 reguló la apertura de 
Incidencia de la banca universal en el sistema financiero venezolano Nava Rosillón, Marbelis Alejandra

la inversión extranjera, la introducción de nuevas formas de intermediación financiera estableciendo un nuevo modelo de banca en el país como es la Banca Universal (BU) y la Banca de Inversión (Bracho et al., 2002) e incrementó el grado de autonomía funcional, administrativa $y$ presupuestaria de la Superintendencia de Bancos y otras Instituciones Financieras (SUDEBAN) (Gómez y Gónzalez, 2001), entre otros aspectos importantes.

Desde entonces, inicia el auge de la $\mathrm{BU}$ en Venezuela como respuesta a las tendencias globalizadoras de la economía mundial y en la búsqueda de modernizar las instituciones financieras nacionales con la visión de incrementar significativamente los niveles de eficiencia, reducir los costos y adaptarse a las nuevas condiciones de competitividad. Este modelo de banca dio paso a un proceso de fusiones $y$ adquisiciones entre diferentes instituciones especializadas (bancos comerciales, hipotecarios, inversión, sociedades de capitalización entre otras), que ha favorecido el escenario financiero del país.

La BU representa el avance experimentado por el sistema bancario venezolano en el transcurso de los años; pues, existen bancos especializados que ejecutan actividades específicas pero actualmente existe mayor facilidad para encontrar todos los servicios en una sola entidad bancaria; puesto que la BU está en capacidad de ofrecer servicios integrales, múltiples y más eficientes con una mejor gestión de su infraestructura al aprovechar la economía de escala y lograr una eficiencia operativa, para ello se han actualizado los sistemas, procedimientos, recursos y políticas (Belloso y Primera, 2005).
Bajo estas premisas, el presente artículo pretende analizar la incidencia de la $\mathrm{BU}$ en el funcionamiento del SFV. El tipo de estudio fue documental (Hurtado, 2007), en el cual buscó puntualizar las características del evento estudiado abordando el proceso investigativo mediante el uso de fuentes secundarias contenidas en textos, revistas científicas especializadas, boletines emitidos por la SUDEBAN y las leyes vigentes pertinentes para la temática (Méndez, 2001). Mediante la contextualización, descripción y especificación de los aspectos más destacados de la BU resaltando los acontecimientos ocurridos en el sistema financiero que dieron origen a este modelo de banca en Venezuela, en los aspectos teóricos y legales de la BU, el proceso de conversión a BU de las instituciones financieras activas y su participación porcentual en la estructura del sistema bancario venezolano.

\section{Aspectos más relevantes del sistema financiero en Venezuela}

En los últimos años, el sistema financiero en Venezuela ha sufrido un proceso de cambios enfocado hacia el mejoramiento de la competitividad y la reducción de los elevados gastos de transformación de la banca venezolana (Garay et al., 2002); pues, el sistema financiero es fundamental para promover el desarrollo económico de un país; en él circula la riqueza y excedentes generados por las familias, empresas e instituciones gubernamentales, ya que en toda economía existen agentes económicos que buscan ahorrar el excedente de sus ingresos y agentes deficitarios de recursos que de- 
mandan financiación; esa demanda de recursos origina el sistema financiero.

Estos agentes no siempre están relacionados entre sí; entonces, surgen instituciones que ejecutan funciones de intermediación financiera; ésta implica una actividad económica (comercial) a escala agregada, donde los intermediarios buscan obtener beneficios monetarios en términos reales (Borgucci, 2001:45); facilitando el flujo de fondos entre oferentes y demandantes, captando recursos financieros de los agentes superavitarios y otorgando préstamos a los agentes deficitarios.

En Venezuela, la actividad de intermediación financiera consiste en la captación de recursos, incluidas las operaciones de mesa de dinero, con la finalidad de otorgar créditos o financiamientos e inversiones en valores, y sólo podrá ser realizada por los bancos, entidades de ahorro y préstamos y demás instituciones financieras reguladas por la LGBOIF (Asamblea Nacional, 2009).

Ahora bien, Bello (2007) define el sistema financiero como el conjunto de instituciones, mercados e instrumentos financieros, que cumplen la misión de canalizar el ahorro financiero hacia los sectores productivos de la economía; para ello, relaciona los agentes económicos que desean invertir el excedente de sus ingresos sobre sus gastos con otros agentes económicos que requieran esos recursos para financiar sus gastos de consumo o de adquisición de activos.

No obstante, la Ley Orgánica del Sistema Financiero Nacional (LOSFIN) aprobada en el mes de Junio de 2010 en el territorio venezolano, en su Artículo 5 establece que el SFV está conformado por el conjunto de instituciones financie- ras públicas, privadas, comunales y cualquier otra forma de organización que operen en el sector bancario, el sector asegurador, el mercado de valores y cualquier otro sector o grupo de instituciones financieras que a juicio del órgano rector deba formar parte de este sistema; incluyéndose las personas naturales y jurídicas usuarias de las instituciones financieras que integran el mismo.

El sistema financiero en Venezuela ha experimentado importantes transformaciones que se acentuaron más a partir de los años noventa (90); pues, el sector evidenció grandes signos de debilidad para los años 1994 y 1995, debido al estallido de una crisis financiera considerada la más fuerte desde 1960. Esta crisis se inició con la intervención y desplome de algunas instituciones financieras como consecuencia de la insolvencia e iliquidez de algunas de ellas, altos costos operativos, fuerte dependencia de ingresos diferentes a los generados por la actividad de intermediación financiera (Bracho et al., 2005); aunado a la organización de entidades financieras bajo los denominados grupos financieros, poca diversidad institucional así como inadecuada supervisión y control de las instituciones financieras, falta de transparencia en la información, insuficiencia de normas prudenciales e insuficiente capitalización de la banca (Arreaza et al., 2002).

Esta situación llevó a nuevos planteamientos que permitieran un mejor funcionamiento del sistema financiero. Entonces, con el transcurso del tiempo se comienzan a evidenciar los resultados de la puesta en marcha de una reforma financiera que significó un reacomodo del SFV; pues, se dio apertura a la inversión 
Incidencia de la banca universal en el sistema financiero venezolano Nava Rosillón, Marbelis Alejandra

extranjera en el país y una significativa proporción del sistema financiero pasó a manos de inversionistas foráneos especialmente españoles, como es el Caso Banco Santander - Central Hispano y Banco Bilbao Vizcaya Argentaria (BBVA) (Borgucci, 2001), cuya participación se tradujo en mejoras a nivel técnico-operativo, fortalecimiento patrimonial, recuperación de la confianza y una posible mejoría en la supervisión y regulación bancaria (Bracho et al., 2002), así como también en un incremento de los niveles de solvencia; además, se produjo un aumento de la capitalización del sistema y los grupos financieros comenzaron a ser sustituidos por los Bancos Universales, lo cual ha permitido una mejor supervisión y control de la actividad bancaria nacional (Gómez y González, 2001).

Sin embargo, el sistema financiero continuaba mostrando signos de fragilidad; pues, las tasas de interés activas mantenían altos niveles y ello no era favorable para reactivar la inversión y las tasas pasivas no estimulaban el ahorro, como consecuencia la intermediación financiera se veía restringida y las instituciones financieras buscaban otras alternativas de ingresos como comisiones por servicios, incrementos de los montos mínimos para la apertura de cuentas, entre otros; aunado a que canalizaban sus colocaciones hacia la inversión en Títulos de Estabilización Monetaria (TEM) emitidos por el Estado. Ello refleja una baja participación del sector bancario en la producción nacional medida a través del nivel de créditos y depósitos (Levy, 2000).

Bajo este contexto, se deduce que el sistema financiero no logró estimular el sistema productivo en el país aún cuando existía un conjunto de medidas consideradas adecuadas y efectivas pero fueron tomadas sin ser atendida la verdadera realidad existente; entonces, las expectativas planteadas no se cumplieron en su totalidad y por ello los bancos universales junto a los bancos comerciales implantaron nuevas estrategias para permanecer en el mercado por lo que se produjo un proceso de fusiones que se inició en noviembre de 1995 y se intensificó para los años 1999 y 2000 (Garay et al., 2002), resultando tan positivo que fortaleció la banca múltiple en el país; la cual inició sus operaciones formalmente con la reforma de la LGBOIF de 1993. Esto ha llevado a un incremento del número de Bancos Universales y a una reducción significativa de bancos especializados en el mercado venezolano.

Desde entonces, la tendencia del SFV apunta hacia la eliminación de instituciones especializadas, para darle paso al concepto de BU (Bracho et al., 2002), reduciendo el número de bancos comerciales y entidades de ahorro y préstamos y emprendiendo un nuevo modelo de banca que ofrece servicios múltiples, con mayor facilidad para los clientes y con un mejor manejo de su infraestructura para lograr mayor eficiencia operativa.

Por otra parte, es importante destacar que para los años 2009 y 2010 , las autoridades monetarias nacionales detectaron irregularidades en diversas instituciones financieras del SFV, como aumento de capitales sin demostrar su origen, transferencias de fondos de una institución a otra, negociaciones fraudulentas y escasez de liquidez para cumplir con los compromisos contraídos. Así, se produjeron intervenciones de algunas entida- 
des bancarias privadas que fueron fusionadas creando nuevas instituciones que pasaron a formar parte de la banca pública; mientras que otras fueron sometidas al proceso de liquidación.

Estos acontecimientos tuvieron lugar debido a que en nuestro país se busca fortalecer la actividad financiera del Estado, reforzar las instituciones que prestan servicios de BU, reagrupar las instituciones especializadas y bancarizar a la población venezolana. Por ello, durante el período 2009-2010 se realizaron nuevas reformas a la Ley del Banco Central de Venezuela, a la LGBOIF y se creó la LOSFIN, que deroga el Decreto $N^{\circ} 411$ con Rango, Valor y Fuerza de la Ley Marco que regula el Sistema Financiero Público del Estado Venezolano de 1999, con miras a adaptar las instituciones financieras a un nuevo esquema productivo nacional.

De allí, es de gran relevancia resaltar que la nueva LISB aprobada por la Asamblea Nacional para el mes de Diciembre del año 2010, contempla la coexistencia de dos modalidades de bancos únicamente, como son bancos universales y bancos microfinancieros; pues, los bancos especializados deben transformarse en BU y para ello deben incrementar su capital en cumplimiento con los requisitos exigidos al respecto; esto, a su vez, evidencia que la tendencia del SFV está enfocada hacia el incremento de la BU y la disminución de la banca especializada.

También esta nueva ley contempla la transformación de la SUDEBAN en la Superintendencia de las Instituciones del Sector Bancario y del Fondo de Garantías de los Depósitos Bancarios (FOGADE) en el Fondo de Protección Social de los Depósitos Bancarios. Sin embargo, es importante destacar que para fines de este estudio se tomará la denominación como Superintendencia de Bancos dado que se obtiene la información de los Boletines publicados por ese ente.

Asimismo, vale destacar que el nuevo marco legal (LOSFIN y LISB) en Venezuela plantea una nueva orientación del escenario financiero al delimitar las funciones y negocios correspondientes a un grupo financiero, pues anula la figura de estos grupos en el país, lo cual indica que las instituciones bancarias no podrán cumplir funciones como aseguradoras y realizar actividades propias del mercado de valores y las empresas de seguros no asumirán responsabilidades bancarias, lo que sugiere que cada institución desempeñará las funciones correspondientes a su actividad. Ahora sólo queda esperar los resultados de estos nuevos esquemas financieros.

\section{Consideraciones teóricas y legales de la banca universal}

Una institución financiera es una entidad o empresa que ejecuta operaciones de banca, cuya actividad fundamental es recibir y concentrar en forma de depósitos los recursos financieros captados del público y colocarlos a disposición de aquellas personas que los requieran en forma de financiamiento con el objetivo de contribuir al desarrollo de actividades productivas y rentables que generen empleo y crecimiento económico en el país.

A juicio de Gitman (2000: 25): "las instituciones financieras son intermediarios que canalizan los ahorros de individuos, empresas y gobiernos a préstamos 
Incidencia de la banca universal en el sistema financiero venezolano Nava Rosillón, Marbelis Alejandra

o inversiones". No obstante, Acedo (1997) considera que estas instituciones constituyen organizaciones especializadas en la acumulación de capitales y en su transferencia a través de su inversión o préstamos; las cuales realizan diversas operaciones como sistema de pagos, transferencias de fondos, compra- venta de acciones, valores, entre otros.

Ahora bien, la BU constituye una institución financiera. Según Díaz (2004: 94) "el Banco Universal es aquella institución bancaria que ofrece la mayoría o todos los servicios financieros que existen en el mercado". Esto refleja que son entidades financieras con competencia para ejecutar todas las operaciones que llevan a cabo los bancos o instituciones financieras especializadas, referidas a todas las actividades implícitas en el proceso de intermediación financiera efectuada por los bancos comerciales, hipotecarios, banca de inversión, banca de desarrollo, arrendadoras financieras, entidades de ahorro y préstamo, entre otros.

Así lo ratifica la LGBOIF (2009) en su Artículo 74 al establecer que "Los Bancos Universales son aquellos que pueden realizar todas la operaciones que, de conformidad con lo establecido en la presente Ley, efectúan los bancos e instituciones financieras especializadas, excepto las de los bancos de segundo piso". Sin embargo, la nueva LISB (2010) en el Artículo 11 expresa que se entiende por Banco Universal a las instituciones que realizan todas las operaciones de intermediación financiera y sus servicios conexos, sin más limitaciones que las expresamente establecidas en la presente Ley.

La BU en Venezuela es una institución que puede operar tanto a nivel na- cional como internacional; pero, para ello debe tener previa autorización de la Superintendencia de las Instituciones del Sector Bancario y cumplir con las disposiciones establecidas en el marco legal vigente.

En la actualidad, la BU ofrece una gestión integral de la institución bancaria, ya que se caracteriza por una nueva cultura organizacional, mayor capacidad para generar nuevos servicios financieros, integrar funcionalmente los procesos y sistemas, posee información más completa en relación a sus clientes y dispone de una estructura más adecuada para enfrentar la competencia globalizada.

Aunado a ello, la BU realiza operaciones de intermediación financiera referidas a:

1) Captación de recursos, como depósitos a la vista y a plazo.

2) Emisión de títulos hipotecarios.

3) Ejecución del leasing financiero o arrendamiento financiero.

4) Actuación como intermediario en el mercado cambiario.

5) Participación en el mercado de valores.

6) Colocación de recursos financieros para proyectos de inversión de mediano y largo plazo.

7) Concesión de créditos hipotecarios y créditos al consumo.

8) Otorgamiento de financiamiento para capital de trabajo.

Dentro de este orden ideas, es importante precisar que en la actividad bancaria en general se desarrollan dos tipos de operaciones fundamentales, las cuales son realizadas por la $\mathrm{BU}$ :

1) Operaciones pasivas, referidas a las operaciones que permiten a las 
instituciones financieras aceptar los fondos de fuentes externas (público) que le sirven de materia prima para efectuar sus operaciones; con las cuales los bancos se convierten en deudores de sus clientes (cuentas corrientes, cuentas de ahorros, depósitos a plazos).

2) Operaciones activas, son aquellas mediante las cuales los bancos colocan los fondos captados a través de las operaciones pasivas, en el mercado en forma de préstamos, convirtiéndose en acreedores de los clientes que reciben el crédito (Bello, 2007).

\subsection{Características de la banca universal}

La BU es una institución financiera cuyas características fundamentales están basadas en los siguientes aspectos:

1) Ofrecer diversidad en instrumentos financieros en pro de una mayor capitalización de recursos, mediante la captación de estos en diferentes modalidades a corto y a largo plazo.

2) Brindar en una misma modalidad, los servicios ofrecidos por las instituciones financieras especializadas.

3) Efectuar operaciones de intermediación financiera en diferentes plazos.

4) Alcanzar y mantener niveles de capitalización superiores a los niveles de la banca especializada.

5) Presentar una estructura organizacional simplificada, sencilla e integrada dada la diversidad de sus negocios.

6) Gran capacidad de adaptación a los constantes cambios del entorno económico y financiero, lo cual se traduce en diversificación de riesgos.
Otro aspecto característico de singular importancia se enfoca en que la BU requiere para operar un capital social mínimo tanto suscrito como pagado de Ciento Setenta Millones de Bolívares (Bs. 170.000.000), si tienen su asiento principal en el Área Metropolitana de Caracas, así como en las ciudades de Guarenas, Guatire, San Antonio de los Altos, Carrizal, Los Teques, Los Valles del Tuy y en el Estado Vargas; y de Ochenta y Cinco Millones (Bs. 85.000.000) si se encuentran ubicadas en cualquier otra región del país, previamente calificadas como Bancos Regionales por la Superintendencia de las Instituciones del Sector Bancario (Asamblea Nacional, 2010).

\subsection{Modalidades para la formación de un banco universal}

Según Acedo (1997), en Venezuela la BU puede formarse mediante tres modalidades como son las fusiones, transformaciones y constituciones de nuevas entidades bancarias.

En los últimos años, las fusiones han constituido el mecanismo más utilizado por las instituciones financieras para alcanzar las dimensiones exigidas por los nuevos esquemas financieros; estas consisten en la unificación de una entidad bancaria con uno o más bancos especializados como consecuencia de problemas de origen financiero existente en algunas de ellos. Se trata de un proceso cuya finalidad es aprovechar las capacidades y ventajas comparativas de las instituciones involucradas para adquirir mayor proporción de acciones de una entidad por parte de la otra, finalizando en la formación de un banco universal. 
Incidencia de la banca universal en el sistema financiero venezolano

Nava Rosillón, Marbelis Alejandra

Un aspecto de singular importancia de las fusiones bancarias se refiere a que estas se pueden realizar mediante dos formas: por incorporación y por absorción. Una fusión por incorporación sucede cuando dos o más instituciones financieras ya existentes crean una nueva institución; para lo cual los componentes del balance de cada una de ellas son agregados al balance de la nueva organización. Mientras que, la fusión por absorción ocurre cuando una institución compra o adquiere una o más instituciones ya existentes las cuales incorporan sus activos, pasivos y patrimonio a la empresa adquiriente.

Por su parte, el proceso de transformación en $\mathrm{BU}$ es una modalidad que se ejecuta cuando una entidad bancaria especialista en un área específica de la intermediación financiera decide ampliar sus operaciones para dedicarse a las actividades de la banca múltiple y se transforma en banca universal asumiendo el desarrollo de todas aquellas operaciones que implica el proceso de intermediación financiera; para ello, debe obtener previa autorización de la SUDEBAN y luego organizar su infraestructura para lograr atender las nuevas áreas del negocio bancario.

En tanto, la constitución se inicia con la creación de un banco universal. Para constituirlo los interesados deben regirse por los procedimientos y requisitos establecidos en el Capítulo II de la LGBOIF referido a la promoción, constitución y funcionamiento de las instituciones financieras en el país, aunado a la obtención de la autorización de la SUDEBAN previa presentación de un plan de negocios, organización y funcionamiento y la estructura accionaria que tendrá el banco universal que va a constituirse.

\section{Cronología de la banca universal durante el período 1996-2010}

En Venezuela, el proceso de conversión a bancos universales, las fusiones y adquisiciones se incrementó significativamente a partir del año 1995; estos procesos buscaban la integración de las instituciones financieras especializadas de un grupo financiero como la banca de inversión y las entidades de ahorro y préstamo.

Según SUDEBAN (2010), las conversiones a BU más destacadas iniciaron en el año 1996, cuando mediante una fusión con Provincial Banco de Inversión, Arrendadora Provincial Sociedad de Arrendamiento Financiero, Fondo Provincial de Activos Líquidos y Fondos de Activos Líquidos Finalven, se transforman a Banco Provincial S.A., Banco Universal, autorizada y publicada para el mes de noviembre de 1996.

Posteriormente, para el mes de enero de 1997 se autoriza y publica la transformación a BU de Banco Mercantil, C.A., Banco Universal a través de la fusión de Banco de Inversión Mercantil, Banco Hipotecario Mercantil, Arrendadora Mercantil y Fondo Mercantil; para ese mismo mes, se produjo la transformación a $\mathrm{BU}$ de Banco Fivenez, S.A.C.A, Banco Universal, mediante una fusión por absorción de Fivenez Arrendadora Financiera, S.A, Inversora Fivenez S.A, y Fivenez Banco Hipotecario, S.A. De igual manera, se transformó a BU el Citibank. N.A. Banco Universal, Sucursal Venezuela para el 30 de enero.

A lo largo del año 1997 se autorizaron y publicaron otras transformaciones a BU entre las cuales se encuentran las si- 
guientes: en el mes de abril, surge el Banco Exterior, C.A. Banco Universal por la fusión de Arrendadora Exterior Sociedad de Arrendamiento Financiero y Fondo Exterior; y el Banco del Orinoco, Banco Universal, se transformó en BU por la fusión de Orinoco Banco de Inversión, Arrendadora del Orinoco Arrendadora Financiera, Banco Hipotecario del Orinoco y Fondo de Inversiones del Orinoco.

Para mayo, se produjo una fusión por absorción entre Arrendadora Internacional, C.A y Fondo Internacional, C.A que dio origen a Interbank, C.A. Banco Universal. El 25 de junio, se transformó a BU el Banco Caroní, C.A. Banco Universal mediante $\mathrm{GO} \mathrm{N}^{\circ}$ 36.234. En septiembre, surge Banesco Banco Universal, C.A fusionando Banesco Arrendadora Financiera y Banesco Fondo de Activos Líquidos; también se transformó a BU, el Banco de Venezuela, S.A según lo publicado en GO N³6.284.

Durante el año 1998 se llevaron a cabo otras transformaciones. En abril, se produjo la transformación a BU del Banco del Caribe, C.A. Banco Universal mediante la fusión con Banco de Inversión del Caribe y Fondo de Activos Líquidos del Caribe. En marzo, se transformó el Banco República, C.A. Banco Universal según GO N³6.408. Del mismo modo, el Banco Caracas, C.A. Banco Universal se transformó a BU a través de la fusión por absorción con el Banco de Inversión Bancaracas, Arrendadora Bancaracas y Fondo de Activos Líquidos Bancaracas según GO No 36.612 en el mes de diciembre.

En el año 1999, sólo se produjo la transformación a BU de Corp Banca, C.A. Banco Universal según GO Nº 36.784 del 10 de septiembre mediante la fusión por absorción de Corp Banco de Inversión, Corp Banco Hipotecario, Corp Arrendadora Financiera, Sociedad Anónima de Arrendamiento Financiero, Corp Fondo de Activos Líquidos y Banco del Orinoco, Banco Universal.

Para el año 2000 continuaron las transformaciones a $\mathrm{BU}$, como es el caso del Banco de Lara, C.A. Banco Universal, para lo cual se fusionó por absorción con el Fondo Lara de Activos Líquidos (FILARA; C.A) según GO No 36.929 del 10 de enero; posteriormente, en el mes de diciembre se autorizó la fusión por absorción de esta institución por parte del Banco Provincial, S.A. Banco Universal según $\mathrm{GO} \mathrm{N}^{\circ}$ 37.093. A finales de este año, surge el BFC Banco Fondo Común, C.A. Banco Universal mediante la fusión por incorporación entre el Banco República C.A. Banco Universal y Fondo Común, Entidad de Ahorro y Préstamo, S.A, transformándose en $\mathrm{BU}$ según $\mathrm{GO} \mathrm{N}^{\circ}$ 37.107 del 27 de Diciembre y autorizándose el cambio de denominación de Fondo Común C.A, Banco Universal a BFC, Banco Fondo Común, C.A. Banco Universal el 31 de marzo de 2006.

Asimismo, en el año 2001 se transforman a BU, Unibanca Banco Universal C.A mediante la fusión por absorción de Caja Familia, Entidad de Ahorro y Préstamo, C.A por parte del Banco Unión con $100 \%$ capital nacional; Norvalbank, C.A. Banco Universal surge como $\mathrm{BU}$ al fusionarse por absorción el Banco Noroco, C.A con Valencia, Entidad de Ahorro y Préstamo. Para el mes de octubre de este año, surge como BU C.A Central Banco Universal a través de la fusión por absorción de Central, Entidad de Ahorro y Préstamo, C.A por parte del Banco Hipotecario Vene- 
Incidencia de la banca universal en el sistema financiero venezolano Nava Rosillón, Marbelis Alejandra

zolano, C.A. También, se transforman a BU, Banco Sofitasa, Banco Universal C.A. mediante la fusión por absorción del Fondo Sofitasa, C.A. y la Arrendadora Sofitasa, C.A., Del Sur, Banco Universal surge al fusionarse por absorción Del Sur Banco de Inversión con Mérida, Entidad de Ahorro y Préstamo y Del Sur, Entidad de Ahorro y Préstamo, C.A.

Para finales de ese año, el Banco Venezolano de Crédito S.A.C.A absorbió Soficrédito Banco de Inversión, C.A y Sogegrédito, C.A de Arrendamiento Financiero transformándose en Venezolano de Crédito S.A., Banco Universal.

Para el año 2002, se fusionan por absorción el Banco Occidental de Descuento, S.A.C.A, Fondo de Activos Líquidos Banco Occidental de Descuento, C.A y Banco Monagas, C.A por parte del Norvalbank, C.A Banco Universal y surge el Banco Occidental de Descuento, Banco Universal, C.A. Por otra parte, el Banco de Venezuela, Banco Universal absorbió el Banco Caracas, Banco Universal para el mes de abril y Unibanca, Banco Universal fue absorbido por Banesco, Banco Universal para el mes de junio. Otra fusión se dio cuando La Margarita, Entidad de Ahorro y Préstamo, C.A absorbió el Banco Canarias de Venezuela, C.A dando lugar al Banco Canarias de Venezuela Banco Universal, C.A para el mes de noviembre.

En el mes de diciembre del año 2003 se publicó la transformación a BU de Provivienda Banco Universal, C.A mediante la fusión por absorción de Provivienda, Entidad de Ahorro y Préstamo, C.A por parte de la Arrendadora Industrial Venezolana, Compañía Anónima de Arrendamiento Financiero, Arrendaven Arrendamiento Financiero, aún cuando el cambio de denominación de Provivienda, Banco Universal C.A a Provivienda, C.A. Banco Universal (BanPro) fue autorizado a partir del 27 de enero de 2004.

Para el año 2004, se transformó a BU el Banco Tequendama, C.A y surge con nueva denominación: Banco Nacional de Crédito, Banco Universal. Este mismo año el Banco de Fomento Regional Los Andes, C.A (Banfoandes) es transformado a BU asumiendo nueva denominación social a Banfoandes, Banco Universal, Compañía Anónima (Banfoandes, C.A).

A partir de agosto de 2005, conjuntamente el Banco Hipotecario Latinoamericana, C.A y TotalBank, C.A, Banco Comercial inician sus operaciones como BU y asumen nueva denominación social, la cual es actualmente Banco del Tesoro, C.A, Banco Universal y TotalBank, C.A, Banco Universal, respectivamente. Para Octubre, surge el Banco Agrícola de Venezuela, C.A, Banco Universal a través de la transformación de la C.A Inversiones Cavendes.

Posteriormente, para el año 2007 Bancoro, C.A asumió nueva denominación social a Bancoro, C.A, Banco Universal Regional al ser transformado en BU y fue autorizado el funcionamiento del Banco Interamericano de Desarrollo, C.A, Banco Universal para el mes de septiembre.

Por último, para el año 2009 se transformó en BU, el Banco Activo, C.A, Banco Comercial denominándose Banco Activo, C.A, Banco Universal. Y surge un nuevo banco para el mes de Diciembre, dada la crisis financiera desatada en el país a finales del año, como es el Banco Bicentenario, Banco Universal, C.A mediante la fusión por incorporación de Banfoandes, C.A, Banco Confederado, S.A, Bolívar 
Banco, C.A y C.A Central Banco Universal autorizado mediante Resolución $\mathrm{N}^{\circ}$ 682.09 del 16 de diciembre de 2009, publicada en la GO No 39.334 del 23 de diciembre de 2009 (SUDEBAN, 2010).

De lo expresado anteriormente se extrae que la BU en Venezuela se ha consolidado en el largo plazo mediante un proceso transformador que ha marcado el desenvolvimiento del sistema financiero durante las últimas dos décadas. Un proceso que ha brindado la oportunidad de crecimiento y desarrollo a las instituciones financieras nacionales logrando convertirlas en entidades con mayor estabilidad, credibilidad, confianza y eficiencia.

\section{Banca universal en la estructura del sistema bancario en Venezuela}

Para el segundo trimestre del año 2010 , el sistema bancario venezolano se encuentra constituido por 47 institu- ciones financieras, de las cuales el $45 \%$ corresponden a Bancos Universales, $19,1 \%$ Bancos Comerciales, 10,6\% Banca de Desarrollo, 6,4\% Banca de Inversión, 2,1\% Banca Hipotecaria; 2,1\% Empresas de Arrendamiento Financiero, 2,1\% Entidades de Ahorro y Préstamo, $4,3 \%$ a los Fondos de Mercado Monetario y el $8,5 \%$ a la Banca con Leyes Especiales (Tabla 1).

De allí, se puede destacar que el subsistema BU tiene la participación más representativa del Sistema Bancario en el país; pues, ya para el año 2000 el número de Bancos Universales totalizaba 16 instituciones teniendo una participación del $19 \%$ dentro del total de instituciones financieras activas (Bracho et al., 2002), mientras que para el año 1994 no operaba este modelo de banca en territorio venezolano. En tanto, para finales el año 2003 el número de Bancos Universales se incrementó a 17 entidades privadas con una participación del $33,3 \%$ en el to-

Tabla 1

Estructura del Sistema Bancario Venezolano (Cifras absolutas y relativas) abril - junio

\begin{tabular}{lcc}
\hline Subsistema & $\mathbf{N}^{\circ}$ & $\%$ \\
\hline Banca Universal & 21 & 45,0 \\
Banca Comercial & 9 & 19,1 \\
Banca de Desarrollo & 5 & 10,6 \\
Banca de Inversión & 3 & 6,4 \\
Banca Hipotecaria & 1 & 2,1 \\
Empresas de Arrendamiento Financiero & 1 & 2,1 \\
Entidades de Ahorro y Préstamo & 1 & 2,1 \\
Fondos del Mercado Monetario & 2 & 4,3 \\
Banca con Leyes Especiales & 4 & 8,5 \\
Total & 47 & 100 \\
\hline
\end{tabular}

Fuente: SUDEBAN (2010). 
Incidencia de la banca universal en el sistema financiero venezolano Nava Rosillón, Marbelis Alejandra

tal de instituciones financieras activas (SUDEBAN, 2004). Estas cifras indican que en el SFV existe una mayor concentración de instituciones en la BU o banca múltiple que se ha acentuado con el transcurso del tiempo dado el proceso de globalización mundial y los nuevos esquemas de modernización del SFV.

Por su parte, la Tabla 2 presenta el número de oficinas y trabajadores del sistema bancario para el segundo trimestre del 2010, donde las oficinas suman 3.739 distribuidas en el territorio nacional, de las cuales el $86,79 \%$ corresponden a las oficinas de la BU las cuales agrupan el $86,33 \%$ de los trabajadores del sistema bancario, demostrando que ocupa la mayor participación dentro del sector financiero y proporciona el más alto porcentaje de empleo a nivel nacional en relación a las demás instituciones financieras activas en el país.

Bajo este contexto, el sistema bancario venezolano se caracteriza por estar dominado por la banca privada nacional, así lo indican las cifras presentadas por SUDEBAN; pues, para el tercer trimestre del año 2009 la banca privada ocupaba el $81,4 \%$ y la banca pública sólo el $18,6 \%$ de un total de 59 instituciones bancarias en el sistema; de cuyas cifras, la BU con capital privado tiene una participación del $35,6 \%$ y con capital público del $6,8 \%$ (Tabla 3$)$.

Sin embargo, para inicios del segundo trimestre de 2010, estas cifras sufrieron variaciones, ya que para finales del año 2009 se produjeron una serie de intervenciones bancarias que incluyeron bancos universales, entre ellos Banco Canarias, Banco Universal; C.A. Central, Banco Universal; Banfoandes, Banco Universal; BanPro, Banco Universal. Posteriormente, a esta situación se creó el Banco Bicentenario, Banco Universal con capital público mediante fusión de estas instituciones y otras con modalidad comercial, originando una disminución y unificación de entidades bancarias espe-

Tabla 2

Sistema bancario

Cantidad de Oficinas y Trabajadores (Cifras Absolutas y Relativas) abril - junio

\begin{tabular}{lcccc}
\hline Subsistema & $\begin{array}{c}\mathbf{N}^{\circ} \text { de } \\
\text { Oficinas }\end{array}$ & $\%$ & $\begin{array}{c}\mathbf{N}^{\circ} \text { de } \\
\text { Trabajadores }\end{array}$ & $\%$ \\
\hline Banca Universal & 3.245 & 86,79 & 64.663 & 86,33 \\
Banca Comercial & 403 & 10,78 & 8.290 & 11,07 \\
Banca de Desarrollo & 31 & 0,83 & 1.108 & 1,48 \\
Banca de Inversión & 3 & 0,83 & 49 & 0,07 \\
Banca Hipotecaria & 1 & 0,03 & 1 & 0,00 \\
Empresas de Arrendamiento Financiero & 1 & 0,03 & 57 & 0,08 \\
Entidades de Ahorro y Préstamo & 47 & 1,26 & 447 & 0,60 \\
Fondos del Mercado Monetario & 2 & 0,05 & 2 & 0,00 \\
Banca con Leyes Especiales & 6 & 0,16 & 285 & 0,38 \\
Total & $\mathbf{3 . 7 3 9}$ & $\mathbf{1 0 0 , 0 0}$ & $\mathbf{7 4 . 9 0 2}$ & $\mathbf{1 0 0 , 0 0}$ \\
\hline
\end{tabular}

Fuente: SUDEBAN (2010). 
Tabla 3

Sistema bancario

Número de bancos y otras instituciones financieras de capital privado y público según subsistema (30-09-09)

\begin{tabular}{lccccc}
\hline & & \multicolumn{4}{c}{$\begin{array}{c}\mathbf{N}^{\circ} \text { de Bancos y otras } \\
\text { Instituciones Financieras }\end{array}$} \\
\hline Subsistema & $\begin{array}{c}\text { Capital } \\
\text { Privado }\end{array}$ & $\%$ & $\begin{array}{c}\text { Capital } \\
\text { Público }\end{array}$ & $\%$ & Total \\
\hline Banca Universal & 21 & 35,6 & 4 & 6,8 & 25 \\
Banca Comercial & 13 & 22,0 & - & - & 13 \\
Banca de Desarrollo & 6 & 10,2 & 1 & 1,7 & 7 \\
Banca de Inversión & 3 & 5,0 & 1 & 1,7 & 4 \\
Banca Hipotecaria & 1 & 1,7 & - & - & 1 \\
Empresas de Arrendamiento Financiero & - & - & 1 & 1,7 & 1 \\
Entidades de Ahorro y Préstamo & 2 & 3,4 & - & - & 2 \\
Fondos del Mercado Monetario & 2 & 3,4 & - & - & 2 \\
Banca con Leyes Especiales & - & - & 4 & 6,8 & 4 \\
Total & 48 & 81,4 & 11 & 18,6 & 59 \\
\hline
\end{tabular}

Fuente: SUDEBAN (2009).

cializadas y surgiendo otra con modalidad de BU.

Así, lo muestra la Tabla 4 donde se aprecian las cifras para el segundo trimestre de 2010, que indican que la banca privada nacional representa el $76,6 \%$ y la banca pública el $23,4 \%$ de un total de 47 entidades bancarias activas; de ello, la BU con capital privado ocupa el $36,2 \%$ y con capital público el 8,5\%.

Aunado a lo anterior, es relevante resaltar que en el año 2010 la BU junto a la Banca Comercial destacaron en el Sistema Bancario con respecto a la distribución del activo, pasivo y captaciones del público; pues, para el primer trimestre el año (enero-marzo) obtuvieron el $97,05 \%$ del total de activos del Sistema, el 97,33\% del total del pasivos y las captaciones del público se situaron en Bs. 262.139 millones.

Mientras que para el segundo trimestre del año alcanzaron $98,25 \%$ del to- tal de activos del Sistema Bancario, $98,60 \%$ del total de pasivos y las captaciones del público alcanzaron Bs. 278.194 millones aumentando en 6,12\% con respecto al trimestre anterior; mostrando así las más altas cifras con respecto al resto de las instituciones financieras del Sistema Bancario Nacional (SUDEBAN, 2010). Estos resultados reflejan la importancia de estas instituciones en el mercado bancario venezolano.

Es importante mencionar que para el año 2010 los principales bancos fueron: Banesco, Banco de Venezuela, BBVA Banco Provincial, Banco Mercantil, Bicentenario Banco Universal y Banco Occidental de Descuento que forman parte de la BU en Venezuela.

Las afirmaciones anteriormente expuestas evidencian la credibilidad y confianza de los agentes económicos al resguardar sus recursos financieros en la 
Incidencia de la banca universal en el sistema financiero venezolano Nava Rosillón, Marbelis Alejandra

Tabla 4

Sistema Bancario

Número de bancos y otras instituciones financieras de capital privado y público, según subsistema $(30 / 06 / 10)$

\begin{tabular}{lccccc}
\hline & & \multicolumn{4}{c}{$\begin{array}{c}N^{\circ} \text { de Bancos y otras } \\
\text { Instituciones Financieras }\end{array}$} \\
\hline Subsistema & $\begin{array}{c}\text { Capital } \\
\text { Privado }\end{array}$ & $\%$ & $\begin{array}{c}\text { Capital } \\
\text { Público }\end{array}$ & $\%$ & Total \\
\hline Banca Universal & 17 & 36,2 & 4 & 8,5 & 21 \\
Banca Comercial & 9 & 19,2 & - & - & 9 \\
Banca de Desarrollo & 4 & 8,5 & 1 & 2,1 & 5 \\
Banca de Inversión & 2 & 4,2 & 1 & 2,1 & 3 \\
Banca Hipotecaria & 1 & 2,1 & - & - & 1 \\
Empresas de Arrendamiento Financiero & - & - & 1 & 2,1 & 1 \\
Entidades de Ahorro y Préstamo & 1 & 2,1 & - & - & 1 \\
Fondos del Mercado Monetario & 2 & 4,2 & - & - & 2 \\
Banca con Leyes Especiales & - & - & 4 & 8,5 & 4 \\
Total & 36 & 76,6 & 11 & 23,4 & 47 \\
\hline
\end{tabular}

Fuente: SUDEBAN (2010).

BU dado el destacado desempeño que ha tenido este modelo de banca en la economía venezolana caracterizado por una gestión integral como institución bancaria, capacidad para generar nuevos servicios financieros, carteras más equilibradas, estructura más idónea ante la competencia globalizada, concepción sistémica del cliente, diversificación de operaciones y mayor eficiencia operativa, lo que se traduce en un comportamiento eficiente como agente de ahorro, agente de colocación, expresión del sistema de pagos, lo cual ha repercutido en forma muy positiva en la estabilidad financiera del país.

\section{Conclusiones}

El estudio de la incidencia la BU en el SFV permite afirmar desde la introduc- ción en el país de esta modalidad de banca se han producido cambios estructurales en el sistema financiero caracterizados por una fuerte tendencia a la disminución de los bancos especializados y un alto incremento de los bancos universales, los cuales se han consolidado a través de un intenso proceso de transformaciones y fusiones de las instituciones financieras, donde ha prevalecido el proceso de fusión por absorción.

En efecto, la inclusión de la BU en nuestro país se enfocó en fortalecer el sistema financiero mediante una nueva visión de cultura organizacional bancaria, el estimulo de la eficiencia y competitividad por la vía de la reducción de los costos, aunado al ofrecimiento de una mayor disposición para el usuario de una variedad de productos y servicios financieros en una sola institución a través de un ser- 
vicio integral, múltiple y eficiente, que permita hacer frente a una cartera de clientes cada vez más exigentes y al mercado bancario tan competitivo de hoy.

En este contexto, la BU juega un papel protagónico en Venezuela, ya que ocupa un significativo lugar en el sistema bancario nacional; así lo demuestran las cifras arrojadas por SUDEBAN al reflejar una mayor concentración de las instituciones financieras activas en la BU, mayores captaciones del público, mayor participación dentro del total de activos y pasivos del sistema bancario, generadora de un alto nivel de empleo, pues, la BU se ha fortalecido con el transcurso de los años creando solidez y ganándose la confianza y credibilidad tanto de los ahorristas como de los inversionistas venezolanos, quienes recurren a estas instituciones para resguardar sus recursos financieros dada su caracterización eficiente como agente de ahorro, colocación y sistema de pagos.

Sin duda alguna, el mapa bancario-financiero venezolano ha cambiado pero aún falta por presenciar transformaciones relevantes, en donde las instituciones especializadas activas en el país sigan los pasos de la banca múltiple y que sea este modelo de banca el que impulse y fortalezca aún más el entorno financiero venezolano.

Para finalizar los resultados presentados en este articulo muestran que, por una parte, el éxito de la BU en Venezuela no se ha logrado en el corto ni en el mediano plazo, sino en el largo plazo; y por otra parte, permiten deducir que es importante para la economía venezolana que el sistema financiero esté integrado por institucio- nes con carácter público y privado, instituciones nacionales y extranjeras, grandes, medianas y pequeñas, con modalidad universal, múltiple e integral que sean entidades bancarias capaces de efectuar un sano y eficiente proceso de intermediación financiera caracterizadas por una adecuada organización, altos niveles de solvencia y gran dinamismo, que permita que estas respondan en forma oportuna a la gran demanda de ahorristas e inversionistas con el fin de promover el desarrollo de actividades productivas rentables generadoras de empleo y crecimiento económico en el país.

\section{Referencias bibliográficas}

Acedo Mendoza, Carlos y Acedo Machado, Alfredo (1997). Instituciones Financieras. Venezuela. Editorial Mc Graw Hill. Pp. 349.

Arreaza, Adriana; Fernández, María; Mirabal, María y Alvarez, Fernando (2002). "Fragilidad Financiera en Venezuela: Determinantes e Indicadores. Banco Central de Venezuela". Gerencia de Investigaciones Económicas. Serie de Documentos de Trabajo $\mathrm{N}^{\circ} 25$. Marzo. Pp. 34-69.

Asamblea Nacional de la República Bolivariana de Venezuela (2010). Ley Orgánica del Sistema Financiero Nacional. Gaceta Oficial №. 39.447. Junio. Venezuela.

Asamblea Nacional de la República Bolivariana de Venezuela (2009). Reforma Parcial del Decreto con Rango, VaIor y Fuerza de la Ley General de Bancos y Otras Instituciones Financieras. Gaceta Oficial №. 5.947. Diciembre. Venezuela.

Asamblea Nacional de la República Bolivariana de Venezuela (2010). Ley de Insti- 
Incidencia de la banca universal en el sistema financiero venezolano

Nava Rosillón, Marbelis Alejandra

tuciones del Sector Bancario. Gaceta Oficial $N^{\circ}$ 6.015. Diciembre. Venezuela. Disponible en línea: www. sudeban.gob.ve. Fecha de Consulta: 27/01/2011.

Bello, R. Gonzalo (2007). Operaciones Bancarias en Venezuela. Teoría y Práctica. $2^{\text {a }}$ Ed. Universidad Católica Andrés Bello. Caracas. Venezuela.

Belloso, Nora y Primera M., Nelly (2005). Sistema de Información en la Banca Universal Venezolana. Revista de Ciencias Sociales. Vol. XI. No. 1. FACES. LUZ. Maracaibo. Venezuela. Pp. 118-130.

Borgucci, Enmanuel (2001). "La Concurrencia Bancaria después de la Crisis Financiera de 1994". Problemas del Desarrollo. Vol. 32. $\mathrm{N}^{\circ}$ 125. UNAM. Abril-Junio. México. Pp 39-70.

Bracho, Yajaira; Ariza, Martha, González, María y Jiménez, Edinson (2002). Fusiones Bancarias en el Sistema Financiero Venezolano. Revista de Ciencias Sociales. Vol. VIII. N ${ }^{\circ} 2$. FACES. LUZ. Maracaibo, Venezuela. Pp. 300-311.

Bracho Yajaira, González, María y Alvarez, Anaís (2005). Comportamiento de la Rentabilidad de la Banca Venezolana. Revista Venezolana de Gerencia. Vol. 10. No 31. LUZ. Maracaibo, Venezuela. Pp. 502-516.

Díaz Mondragón, Manuel (2004). “Los Bancos Globales y sus Implicaciones en México". Economía Informa. N $N^{\circ} 325$. Abril. México. Pp. 91-100.

Garay, Urbi; González, Maximiliano; Gosende, Javier y Mota, Alejandro (2002). Oferta Pública para la toma de control en Venezuela: Estudio de Eventos para el Caso Banco de Venezuela Banco Caracas. Academia. Revista Latinoamericana de Administración. Universidad de los Andes. №29. Bogotá,
Colombia. Pp. 29-44. En línea: http:// redalyc.uaemex.mx. Consulta: 20/05/ 2010.

Gitman, Lawrence (2000). Principios de Administración Financiera. $8^{a}$ Edición. Prentice Hall Hispanoamericana. México. Pp. 593.

Gómez, Pável y González, Rosa A. (2001). La Autonomía Administrativa de las Instituciones Gubernamentales en Venezuela: El Caso de la Superintendencia de Bancos y Otras Instituciones Financieras (SUDEBAN). Instituto de Estudios Superiores de Administración. Banco Interamericano de Desarrollo. Washington, Estados Unidos. Disponible en: www.idbdocs.iadb.org/getdocument.aspx? docnum =78806. 12/08/2010.

Hurtado, Jacqueline (2007). El Proyecto de Investigación. Metodología de la investigación Holística. ( $5^{\mathrm{a}}$ ed.). Caracas, Venezuela. Quirón. Pp. 183.

Levy Carciente, Sary. (2000). Sistemas Bancarios y Globalización. Experiencia Venezolana. Revista Venezolana de Análisis de Coyuntura. Vol. VI. № 2 . Julio-Diciembre. Pp. 57-83.

Méndez, Carlos (2001). Metodología. Diseño y Desarrollo del Proceso de Investigación. $3^{\mathrm{a}}$ Edición. Colombia. Mc Graw Hill. Pp. 246.

Superintendencia de Bancos y otras Instituciones Financieras (2004). Boletín Trimestral. Indicadores Financieros. Año 11. No 43. Octubre-Diciembre del Año 2003. Caracas, Venezuela.

Superintendencia de Bancos y otras Instituciones Financieras (2009). Boletín Trimestral. Indicadores Financieros. Año 16. № 67. Julio-Septiembre. Caracas, Venezuela.

Superintendencia de Bancos y otras Instituciones Financieras (2010). Boletín Trimestral. Indicadores Financieros. 
Año 17. № 69 . Enero-Marzo. Caracas. Venezuela. Mayo. Disponible en línea: www.sudeban.gob.ve. Fecha de Consulta: 10/11/2010.

Superintendencia de Bancos y otras Instituciones Financieras (2010). Boletín Tri- mestral. Indicadores Financieros. Año 17. $N^{\circ}$ 70. Abril-Junio. Caracas. Venezuela. Agosto. Disponible en línea: www.sudeban.gob.ve. Fecha de Consulta: 10/01/2011. 